UMTRI-2011-23

JUNE 2011

\title{
Recent Changes in the Age Composition of U.S. DRIVERS: IMPLICATIONS FOR THE EXTENT, SAFETY, AND ENVIRONMENTAL CONSEQUENCES of PERsonal TRANSPORTATION
}

\author{
Michael SivaK \\ BRANDON SCHOETTLE
}

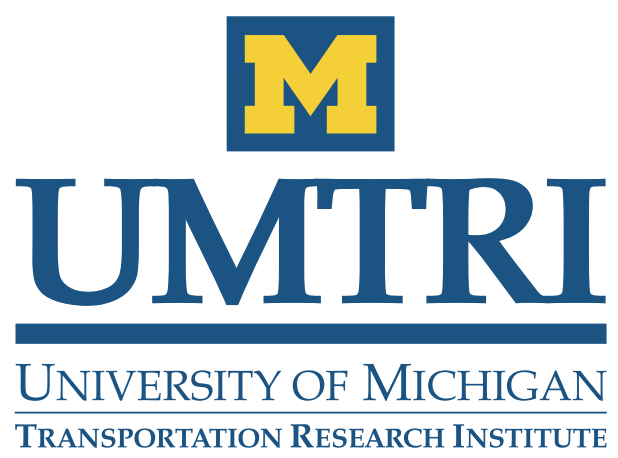


RECENT CHANGES IN THE AGE COMPOSITION OF U.S. DRIVERS:

IMPLICATIONS FOR THE EXTENT, SAFETY, AND ENVIRONMENTAL

CONSEQUENCES OF PERSONAL TRANSPORTATION

Michael Sivak

Brandon Schoettle

The University of Michigan

Transportation Research Institute

Ann Arbor, Michigan 48109-2150

U.S.A.

Report No. UMTRI-2011-23

June 2011 


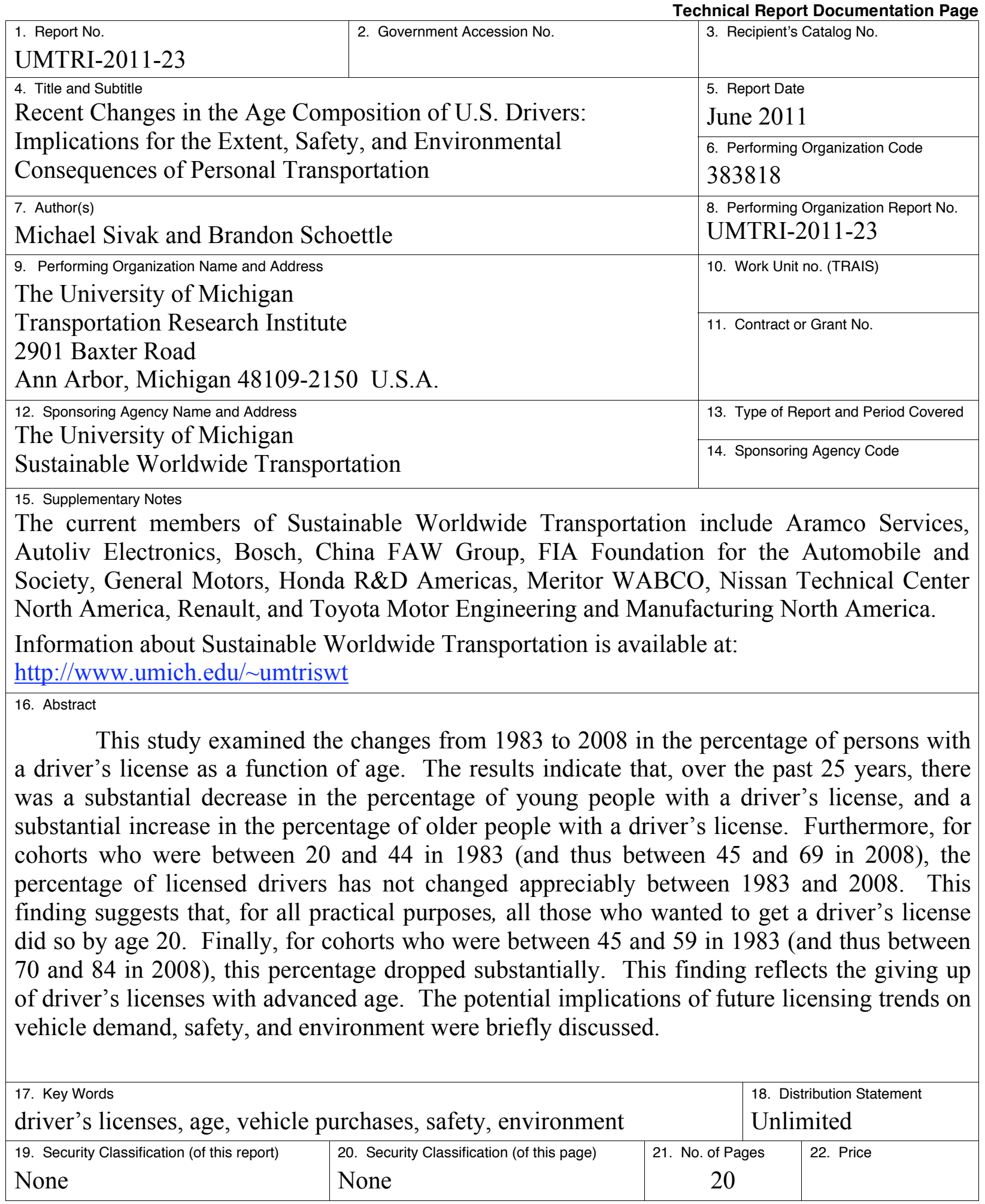




\section{Acknowledgments}

This research was supported by Sustainable Worldwide Transportation (http://www.umich.edu/ umtriswt). The current members of this research consortium are Aramco Services, Autoliv Electronics, Bosch, China FAW Group, FIA Foundation for the Automobile and Society, General Motors, Honda R\&D Americas, Meritor WABCO, Nissan Technical Center North America, Renault, and Toyota Motor Engineering and Manufacturing North America. 


\section{Contents}

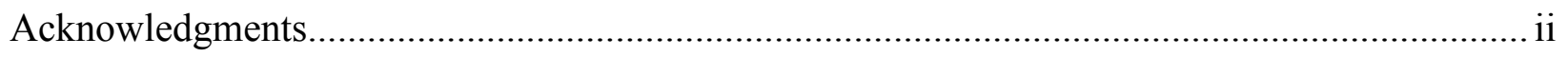

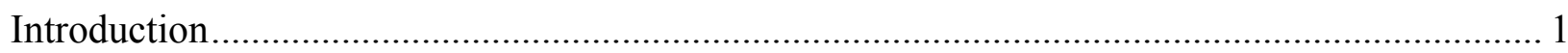

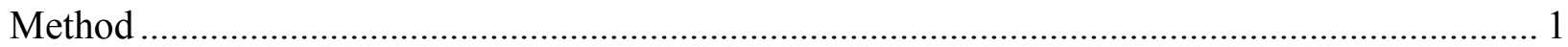

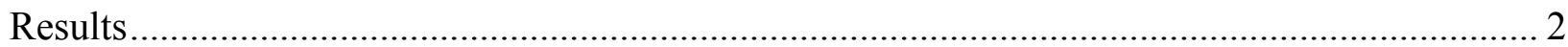

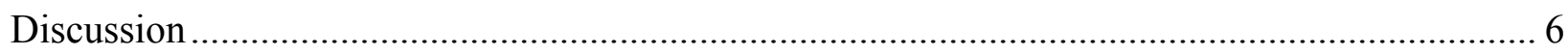

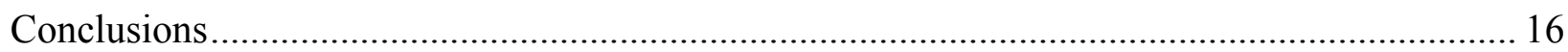

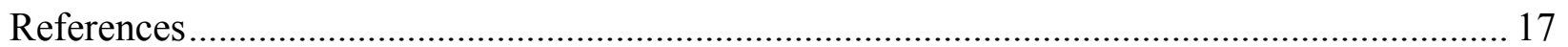




\title{
Introduction
}

This report examines the recent changes in the demographics of licensed U.S. drivers. The motivation for this analysis is that driver age affects a variety of important aspects of road transportation. On the most fundamental level, age affects decisions about the balance of driving and other modes of transportation (NHTS, 2011), and about the amount of driving (NHTS, 2011). Next, age influences the type of vehicle that a driver purchases in terms of cost and vehicle class (and thus environmental impact) (BLS, 2010; McManus, Senter, Curtin, and Garver, 2009). Finally, once behind the wheel, driver age has a large effect on safety, both in terms of safety per distance driven and safety per person (Massie, Green, and Campbell, 1995; Ferguson, Teoh, and McCartt, 2007).

\begin{abstract}
Method
Changes in licensing of U.S. drivers were examined over a period of 25 years, from 1983 to 2008. Of interest were two sets of statistics: licensed drivers as a percentage of their respective age group, and drivers in each age group as a percentage of all drivers. The data came from FHWA $(1984,2009)$.
\end{abstract}




\section{Results}

Licensed drivers as percentages of their respective age group for 1983 and 2008 are shown in Table 1 and Figure 1. There are two main results. First, fewer persons younger than 45 had driver's licenses in 2008 than in 1983. The largest difference involves the youngest drivers. For example, in 2008 only $31 \%$ of 16 -year-olds had a driver's license, as compared to $46 \%$ in 1983 . The analogous values for 17 -year-olds are $50 \%$ and $69 \%$, respectively. The second main result is that a larger percentage of persons who are older than 45 had driver's licenses in 2008 than in 1983. The largest difference involves the oldest drivers. For example, in 2008 about $78 \%$ of those 70 years of age and older had a driver's license, as compared to $55 \%$ in 1983 . The analogous values for those between 65 and 69 years of age are 94\% and 79\%, respectively.

Table 1

Licensed drivers as a percentage of their age-group population.

\begin{tabular}{|c|c|c|}
\hline Age & 1983 & 2008 \\
\hline 16 & 46.2 & 31.1 \\
\hline 17 & 68.9 & 50.0 \\
\hline 18 & 80.4 & 65.4 \\
\hline 19 & 87.3 & 75.5 \\
\hline $20-24$ & 91.8 & 82.0 \\
\hline $25-29$ & 95.6 & 86.3 \\
\hline $30-34$ & 96.5 & 90.6 \\
\hline $35-39$ & 94.9 & 91.7 \\
\hline $40-44$ & 92.2 & 91.9 \\
\hline $45-49$ & 92.5 & 93.0 \\
\hline $50-54$ & 91.4 & 94.2 \\
\hline $55-59$ & 88.2 & 94.9 \\
\hline $60-64$ & 83.8 & 95.9 \\
\hline $65-69$ & 79.2 & 94.0 \\
\hline$\geq 70$ & 55.0 & 78.4 \\
\hline
\end{tabular}


In addition, the age of peak licensing increased during the 25 years examined. In 1983, the peak occurred for those between 30 and 34 years, while in 2008 it peaked for those between 60 and 64 years. For both years, the peaks were about the same (96\%).

Table 2 and Figure 2 present licensed drivers as percentages of total licensed drivers by age group. In 1983, the largest group of drivers included those between 25 and 29 years of age (13\%). In contrast, in 2008, the largest group included those 70 years and older $(10 \%)$.

Table 2

Licensed drivers as percentage of total licensed drivers, by age.

\begin{tabular}{|c|r|r|}
\hline Age & 1983 & 2008 \\
\hline$\leq 19$ & 7.4 & 4.8 \\
\hline $20-24$ & 12.9 & 8.3 \\
\hline $25-29$ & 13.1 & 8.8 \\
\hline $30-34$ & 11.9 & 8.5 \\
\hline $35-39$ & 10.0 & 9.2 \\
\hline $40-44$ & 7.9 & 9.5 \\
\hline $45-49$ & 6.7 & 10.2 \\
\hline $50-54$ & 6.6 & 9.7 \\
\hline $55-59$ & 6.6 & 8.5 \\
\hline $60-64$ & 5.8 & 7.0 \\
\hline $65-69$ & 4.6 & 5.1 \\
\hline$\geq 70$ & 6.5 & 10.4 \\
\hline
\end{tabular}




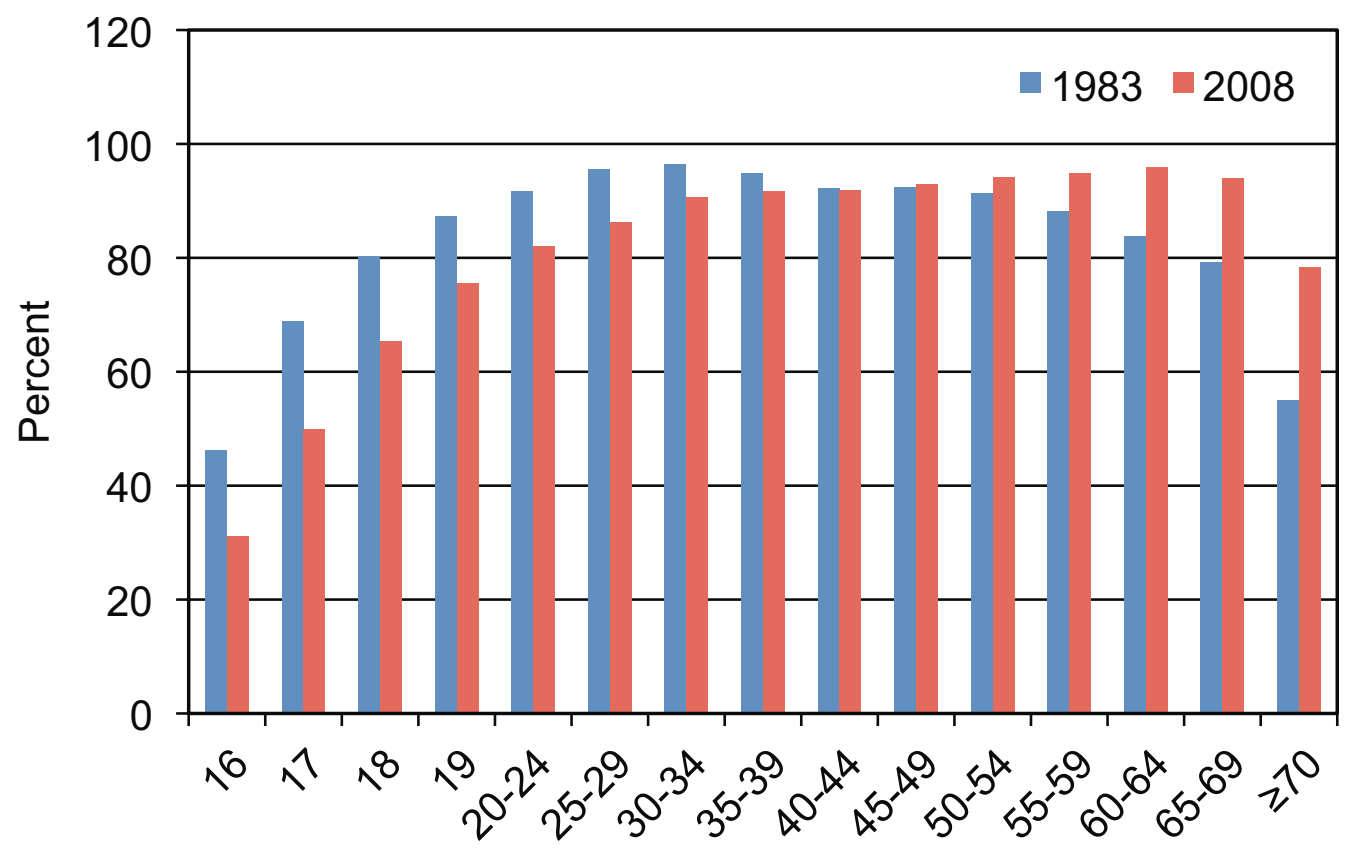

Age group

Figure 1. Licensed drivers as a percentage of their age-group population.

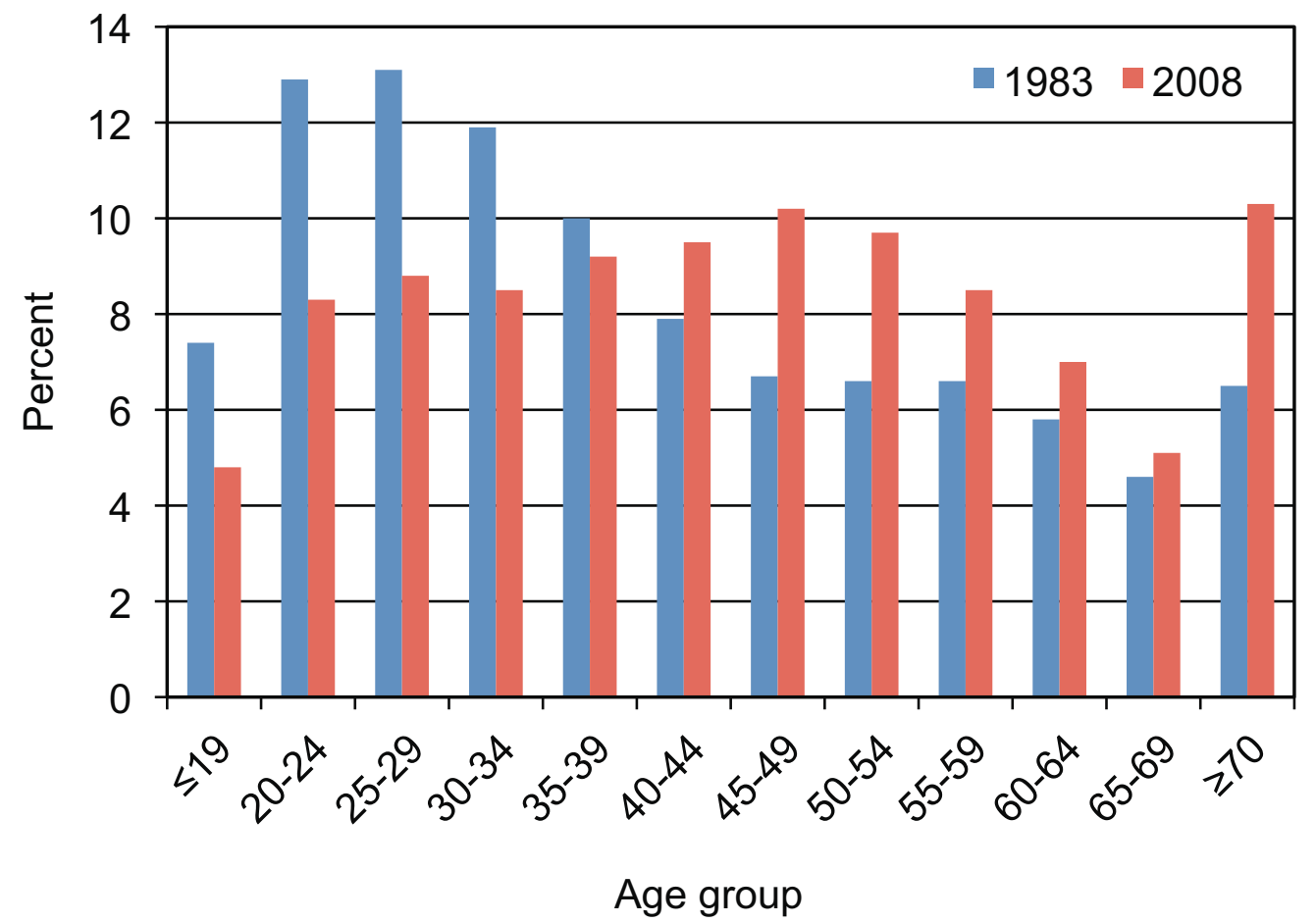

Figure 2. Licensed drivers as percentage of total licensed drivers, by age. 
Table 3 documents the changes in driver licensing between 1983 and 2008 by cohort groups. ${ }^{1}$ For example, the first entry in Table 3 shows that the percentage of person with a driver's license who were 20 to 24 in 1983 (and who came to be 45 to 49 in 2008) increased by $1.3 \%$ between 1983 and 2008. (This is a percentage change of a percentage.) Overall, the data in Table 3 indicate that there was no appreciable change in the licensing from 1983 to 2008 for those who were between 20 and 44 in 1983 (and who came to be between 45 and 49 in 2008). Specifically, these percentage changes in the percentages of those with driver's licenses in 2008 versus 1983 were all within $\pm 2 \%$. On the other hand, there were more substantial decreases in the licensing for those who were between 45 and 60 in 1983 (and who came to be between 70 and 84 in 2008). These decreases were $3.4 \%, 7.8 \%$, and $13.2 \%$ for those who in 2008 were 70 to 74,75 to 79 , and 80 to 84 , respectively. ${ }^{2}$

Table 3

Licensed drivers as a percentage of their age-group population, by cohort groups.

\begin{tabular}{|c|c|c|c|c|}
\hline \multicolumn{2}{|c|}{ Age } & \multicolumn{3}{c|}{$\%$ licensed drivers } \\
\hline In 1983 & In 2008 & In 1983 & In 2008 & $\begin{array}{c}\% \text { change of } \\
\% \text { in 2008 vs. } \\
\% \text { in 1983 }\end{array}$ \\
\hline $20-24$ & $45-49$ & 91.8 & 93.0 & +1.3 \\
\hline $25-29$ & $50-54$ & 95.6 & 94.2 & -1.5 \\
\hline $30-34$ & $55-59$ & 96.5 & 94.9 & -1.7 \\
\hline $35-39$ & $60-64$ & 94.9 & 95.9 & +1.1 \\
\hline $40-44$ & $65-69$ & 92.2 & 94.0 & +2.0 \\
\hline $45-49$ & $70-74$ & 92.5 & 89.4 & -3.4 \\
\hline $50-54$ & $75-79$ & 91.4 & 84.3 & -7.8 \\
\hline $55-59$ & $80-84$ & 88.2 & 76.6 & -13.2 \\
\hline
\end{tabular}

\footnotetext{
${ }^{1}$ The data are from Table 1, except that the 2008 data for those who were between 70 and 84 in 2008 are from the original source (FHWA, 2009).

${ }^{2}$ Because of deaths, immigration/emigration, etc., the age cohorts in Table 3 do not contain identical persons.
} 


\section{Discussion}

There are four main findings of this study:

(1) Over the past 25 years, there has been a substantial reduction in the percentage of young people that have a driver's license.

(2) During the same time period, there has been a substantial increase in the percentage of older people that have a driver's license.

(3) For cohorts who were between 20 and 44 in 1983 (and between 45 and 69 in 2008), the percentage of persons with a driver's license has not changed appreciably between 1983 and 2008. This finding suggests that, for all practical purposes, for the cohorts born between 1939 and 1963, all those who wanted to get a driver's license did so by age 20.

(4) For cohorts who were between 45 and 59 in 1983 (and between 70 and 84 in 2008), the percentage of persons with a driver's license has decreased substantially between 1983 and 2008. This finding reflects the giving up of driver's licenses with advanced age.

The future evolution of these trends will have potentially major implications for future transportation and its consequences. Specifically, licensing trends will likely affect the future amount and nature of transportation, transportation mode selected, vehicles purchased, the safety of travel, and the environmental consequences of travel.

What follows is a brief discussion of age effects on amount of travel, travel modes, vehicle-purchase expenditures, types of vehicles purchased, amount of driving, and risk per distance traveled. 


\section{Amount of travel}

The number of trips (by all modes) follows an inverted-U-shape function. The number of trips peaks in the age group between 41 and 45 years of age, with the oldest traveling the least (Table 4). For example, the mean numbers of trips per day for those 16 to 20,41 to 45 , and 71 and above are $3.5,4.5$, and 3.1 , respectively.

Table 4

Mean number of trips (by all modes), by age.

The data are for 2009 (NHTS, 2011).

\begin{tabular}{|c|c|}
\hline Age & $\begin{array}{c}\text { Mean number } \\
\text { of trips }\end{array}$ \\
\hline \hline $16-20$ & 3.5 \\
\hline $21-25$ & 3.6 \\
\hline $26-30$ & 3.9 \\
\hline $31-35$ & 4.2 \\
\hline $36-40$ & 4.4 \\
\hline $41-45$ & 4.5 \\
\hline $46-50$ & 4.3 \\
\hline $51-55$ & 4.1 \\
\hline $56-60$ & 4.0 \\
\hline $61-65$ & 3.9 \\
\hline $66-70$ & 3.8 \\
\hline$\geq 71$ & 3.1 \\
\hline
\end{tabular}




\section{Travel modes}

Table 5 presents mean annual expenditures for personal and public transportation (for the head of household). These expenditures follow an inverted-U-shape function, with those between 45 and 54 spending the most for both. The expenditure for public transportation (as a percentage of the expenses for personal transportation) is greatest for those 75 years of age and older.

Table 5

Mean annual expenditures for personal and public transportation for the head of household, by age. The data are for 2009 (BLS, 2010).

\begin{tabular}{|c|c|c|c|}
\hline \multirow[b]{2}{*}{ Age } & \multicolumn{3}{|c|}{ Mean annual expenditures } \\
\hline & $\begin{array}{l}\text { Personal transportation, } \\
\text { including vehicle } \\
\text { purchase, gasoline, } \\
\text { insurance, etc. }(\$)\end{array}$ & $\begin{array}{l}\text { Public transportation } \\
\text { (\$) }\end{array}$ & $\begin{array}{l}\text { Public-transportation } \\
\text { expenses as \% of } \\
\text { personal-transportation } \\
\text { expenses }\end{array}$ \\
\hline $18-24$ & 5,100 & 230 & 5 \\
\hline $25-34$ & 7,200 & 490 & 7 \\
\hline $35-44$ & 7,800 & 550 & 7 \\
\hline $45-54$ & 8,800 & 580 & 7 \\
\hline $55-64$ & 7,800 & 540 & 7 \\
\hline $65-74$ & 6,700 & 380 & 6 \\
\hline$\geq 75$ & 3,300 & 300 & 9 \\
\hline
\end{tabular}


Transportation mode to work by age is documented in Table 6. The use of personal vehicles for commuting by age follows an inverted-U-shape function. The use peaks for those between 51 and 55 years of age (94.6\%). The youngest commuters (those between 16 and 20) use personal vehicles the least (90.8\%).

Public transportation is used most by those 21 through $25(3.5 \%)$, and least by those 71 and older $(1.8 \%)$. The use of bicycling for commuting declines monotonically with age. Specifically, the highest use is for those 16 through $20(1.3 \%)$, and the lowest for those 71 and older $(0.2 \%)$. Finally, the percentage of those walking to work has a Ushape function. The lowest percentage is for those 36 through 60 (about 1.5\%), while the highest is for those 16 through $20(4.2 \%)$ and those 71 and older (3.5\%).

Table 6

Transportation mode to work, by age. The entries are percentages.

The data are for 2009 (NHTS, 2011).

\begin{tabular}{|c|c|c|c|c|c|}
\hline \multirow{2}{*}{ Age } & \multicolumn{5}{|c|}{ Transportation mode } \\
\cline { 2 - 6 } & $\begin{array}{c}\text { Personal } \\
\text { vehicle }\end{array}$ & $\begin{array}{c}\text { Public } \\
\text { transportation }\end{array}$ & Bicycle & Walk & Other \\
\hline \hline $16-20$ & 90.8 & 2.6 & 1.3 & 4.2 & 1.1 \\
\hline $21-25$ & 91.5 & 3.5 & 0.9 & 2.8 & 1.3 \\
\hline $26-30$ & 92.3 & 3.3 & 0.7 & 2.4 & 1.3 \\
\hline $31-35$ & 93.5 & 2.9 & 0.7 & 1.8 & 1.1 \\
\hline $36-40$ & 94.0 & 2.9 & 0.7 & 1.5 & 0.9 \\
\hline $41-45$ & 94.5 & 2.5 & 0.6 & 1.5 & 0.9 \\
\hline $46-50$ & 94.3 & 2.6 & 0.6 & 1.6 & 0.9 \\
\hline $51-55$ & 94.6 & 2.5 & 0.5 & 1.5 & 0.9 \\
\hline $56-60$ & 94.5 & 2.6 & 0.4 & 1.6 & 0.9 \\
\hline $61-65$ & 94.3 & 2.2 & 0.3 & 2.3 & 0.9 \\
\hline $66-70$ & 93.8 & 2.1 & 0.2 & 2.7 & 1.2 \\
\hline$\geq 71$ & 93.4 & 1.8 & 0.2 & 3.5 & 1.1 \\
\hline
\end{tabular}




\section{Vehicle-purchase expenditures}

Mean annual expenditures for vehicle purchases for the head of household are listed in Table 7. (These expenditures are subsets of the personal-transportation expenditures listed in Table 5.) The expenditures by age follow an inverted-U-shape function. The expenditures peak for those between 45 and 54 years of age. This age group spends about 1.4 times more for vehicle purchases than those between 18 and 24 years of age, and about 2.9 times more than those 75 and older.

Table 7

Mean annual vehicle purchases for the head of household, by age.

The data are for 2009 (BLS, 2010).

\begin{tabular}{|c|c|}
\hline Age & $\begin{array}{c}\text { Vehicle } \\
\text { purchases }(\$)\end{array}$ \\
\hline $18-24$ & 2,300 \\
\hline $25-34$ & 2,800 \\
\hline $35-44$ & 2,800 \\
\hline $45-54$ & 3,200 \\
\hline $55-64$ & 2,800 \\
\hline $65-74$ & 2,600 \\
\hline$\geq 75$ & 1,100 \\
\hline
\end{tabular}

\section{Types of vehicles purchased}

A recent analysis suggests that the proportion of cars as a share of all light-duty vehicles by age of the head of household is a U-shaped function (McManus et al., 2009), with the lowest proportion for those between 35 and 40 years of age. Furthermore, the proportion of households that have only vehicles produced by domestic manufacturers tends to be a monotonically increasing function with the age of the head of household (McManus et al., 2009). 
Amount of driving

Distance driven is one of the factors that affect the amount of vehicle emissions and road safety. The amount of driving by age is an inverted-U-shape (Table 8). The amount peaks for drivers between 40 and 44 years of age. These drivers accumulate about 9 times the mileage of the 16-year-olds, and about 2.4 times the mileage of those 70 years and older.

Table 8

Mean annual miles driven, by age.

The data are for 2009 (NHTS, 2011).

\begin{tabular}{|c|c|}
\hline Age & Miles driven \\
\hline \hline 16 & 1,700 \\
\hline 17 & 4,400 \\
\hline 18 & 7,000 \\
\hline 19 & 9,000 \\
\hline $20-24$ & 11,800 \\
\hline $25-29$ & 14,200 \\
\hline $30-34$ & 15,200 \\
\hline $35-39$ & 15,200 \\
\hline $40-44$ & 15,400 \\
\hline $45-49$ & 15,200 \\
\hline $50-54$ & 14,600 \\
\hline $55-59$ & 13,000 \\
\hline $60-64$ & 11,900 \\
\hline $65-69$ & 10,300 \\
\hline$\geq 70$ & 6,400 \\
\hline
\end{tabular}


Risk per distance driven

Involvement in fatal crashes by age is a U-shaped function (Massie, Green, and Campbell, 1995). As shown in Table 9, the involvement is lowest for those 40 through 49 years of age (in 1990, 1.8 per 100 million miles travelled). In contrast, the highest rates are for those 16 through 19 years of age (9.2 per 100 million miles) and those 75 years of age and older (11.5 per 100 million miles).

Table 9

Involvement in fatal crashes, by age.

The data are for 1990 (Massie, Green, and Campbell, 1995).

\begin{tabular}{|c|c|}
\hline Age & $\begin{array}{c}\text { Fatality rate } \\
\text { per 100 } \\
\text { million miles }\end{array}$ \\
\hline \hline $16-19$ & 9.2 \\
\hline $20-24$ & 4.8 \\
\hline $25-29$ & 3.1 \\
\hline $30-34$ & 2.4 \\
\hline $35-39$ & 2.0 \\
\hline $40-44$ & 1.8 \\
\hline $45-49$ & 1.8 \\
\hline $50-54$ & 2.0 \\
\hline $55-59$ & 2.0 \\
\hline $60-64$ & 2.5 \\
\hline $65-69$ & 3.8 \\
\hline $70-74$ & 5.2 \\
\hline$\geq 75$ & 11.5 \\
\hline
\end{tabular}




\section{Future trends}

What can we expect over the next 25 years in terms of driver licensing? The changes from 2008 to 2033 will not necessarily mimic the changes experienced from 1983 to 2008. However, as an illustrative, hypothetical example, let's assume that the trends from 1983 to 2008 will continue. Under such a scenario, we can then use the percentage changes in the percentages from 1983 to 2008 of licensed drivers that were derived for different age groups in the rightmost column of Table 3. In Table 10, these percentage changes were applied to the licensing percentages in 2008 to derive licensing percentages in 2033.

Table 10

A hypothetical scenario of licensing trends from 1983 to 2008 continuing through 2033.

\begin{tabular}{|c|c|c|c|c|}
\hline \multicolumn{2}{|c|}{ Age } & \multirow{2}{*}{$\begin{array}{c}\text { Percentage } \\
\text { change for } \\
\text { the same }\end{array}$} & \multicolumn{2}{c|}{$\begin{array}{c}\text { Percentage of } \\
\text { licensed drivers }\end{array}$} \\
\cline { 5 - 6 } In 2008 & In 2033 & $\begin{array}{c}\text { age group } \\
\text { from 1983 } \\
\text { to 2008 }\end{array}$ & In $2008^{2}$ & In 2033 \\
\hline $20-24$ & $45-49$ & +1.3 & 82.0 & 83.1 \\
\hline $25-29$ & $50-54$ & -1.5 & 86.3 & 85.0 \\
\hline $30-34$ & $55-59$ & -1.7 & 90.6 & 89.1 \\
\hline $35-39$ & $60-64$ & +1.1 & 91.7 & 92.7 \\
\hline $40-44$ & $65-69$ & +2.0 & 91.9 & 93.7 \\
\hline $45-49$ & $70-74$ & -3.3 & 93.0 & 90.9 \\
\hline $50-54$ & $75-79$ & -7.7 & 94.2 & 86.9 \\
\hline $55-59$ & $80-84$ & -13.2 & 94.9 & 82.4 \\
\hline
\end{tabular}

${ }^{1}$ From Table 3.

${ }^{2}$ From Table 1.

${ }^{3}$ The percentage in Column 4 adjusted by the percentage in Column 3. 
Table 11 compares the derived percentages for 2033 (Column 5 in Table 10) with the corresponding percentages for the same age groups (but different cohorts) in 2008 (Column 3 in Table 1).

Table 11

Licensed drivers as a percentage of their age-group population. (The 2008 data are from Table 1. The 2033 data are derived using a hypothetical scenario under which the licensing trends from 1983 to 2008 will continue through 2033.)

\begin{tabular}{|c|c|c|}
\hline Age & 2008 & 2033 \\
\hline $45-49$ & 93.0 & 83.1 \\
\hline $50-54$ & 94.2 & 85.0 \\
\hline $55-59$ & 94.9 & 89.1 \\
\hline $60-64$ & 95.9 & 92.7 \\
\hline $65-69$ & 94.0 & 93.7 \\
\hline $70-74$ & 89.4 & 90.9 \\
\hline $75-80$ & 84.3 & 86.4 \\
\hline $80-84$ & 76.6 & 82.4 \\
\hline
\end{tabular}

The information in Table 11 indicates that, under this hypothetical scenario, the percentage of licensed drivers 45 to 69 would be smaller in 2033 than was the case in 2008, with the largest decrease for those between 45 and 49 (a decrease of about 10\%). Conversely, the percentage of licensed drivers between 70 and 84 would be greater in 2033 than was the case in 2008, with the largest increase for those between 80 and 84 (an increase of about $8 \%$ ). Consequently, under this hypothetical scenario, we can expect the following changes from the current status quo:

(1) a decrease in the number of trips (because the number of trips peaks for those between 45 to 50 ; see Table 4),

(2) a decrease in the expenditures for personal transportation, including those for vehicle purchases (because these expenditures peak for those between 45 and 54; see Tables 5 and 7), 
(3) a decrease in the distances driven (because, after age 40, the distance driven is a monotonically decreasing function with increasing age; see Table 8), and therefore a decrease in vehicle emissions, and

(4) an increase in the fatality rate per distance driven (because this rate is lowest for those between 40 and 49; see Table 9).

The hypothetical scenario presented above is an example of how future trend scenarios of driver licensing can be combined with known age effects to estimate the consequences on future vehicle demand, safety, and environment. However, this scenario should not be considered a forecast. 


\section{Conclusions}

This study examined the changes from 1983 to 2008 in the percentage of persons with driver's license as a function of age. The results indicate that, over the past 25 years, there was a substantial decrease in the percentage of young people with a driver's license, and a substantial increase in the percentage of older people with a driver's license. Furthermore, for cohorts who were between 20 and 44 in 1983 (and thus between 45 and 69 in 2008), the percentage of licensed drivers has not changed appreciably between 1983 and 2008. This finding suggests that, for all practical purposes, all those who wanted to get a driver's license did so by age 20. Finally, for cohorts who were between 45 and 59 in 1983 (and thus between 70 and 84 in 2008), this percentage dropped substantially. This finding reflects the giving up of driver's licenses with advanced age. The potential implications of future licensing trends on vehicle demand, safety, and environment were briefly discussed. 


\section{References}

Bureau of Labor Statistics. (2010). Consumer Expenditure Survey - 2009 expenditure tables. Retrieved May 24, 2011 from http://www.bls.gov/cex/csxstnd.htm.

Ferguson, S.A., Teoh, E.R., and McCartt, A.T. (2007). Progress in teenage crash risk during the last decade. Journal of Safety Research, 38, 137-145.

FHWA [Federal Highway Administration]. (1984). Highway statistics 1983. Retrieved May 17, 2011 from http://www.fhwa.dot.gov/policyinformation/statistics.cfm.

FHWA [Federal Highway Administration]. (2009). Highway statistics 2008. Retrieved May 17, 2011 from http://www.fhwa.dot.gov/policyinformation/statistics.cfm.

Massie, D.L., Green, P.E., and Campbell, K.L. (1997). Crash involvement rates by driver gender and the role of average annual mileage. Accident Analysis and Prevention, $29,675-685$.

McManus, W., Senter Jr., R., Curtin, R., and Garver, M. (2009). The demographic threat to Detroit's automakers. Journal of Targeting, Measurement and Analysis for Marketing, 17(2), 81-92.

NHTS [National Household Travel Survey]. (2011). 2009 National Household Travel Survey. Retrieved May 31, 2011 from http://nhts.ornl.gov/. 